\title{
Avaliação da proteção conferida pela vacina antimeningocócica BC no Estado de Santa Catarina, Brazil, 1990/92
}

\section{Evaluation of the protective efficacy of an antimeningococcal vaccine for serogroups $B$ and $C$ Neisseria meningitidis infections in Brazil, 1990/92}

\section{Eduardo de A. Costa, Horiovaldo Martins e Carlos H. Klein}

Departamento de Epidemiologia e Métodos Quantitativos da Escola Nacional de Saúde Pública. Rio de Janeiro, RJ - Brasil (E.A.C.,C.H.K.), Serviço de Vigilância Epidemiológica da Secretaria de Saúde do Estado de Santa Catarina. Florianópolis, SC-Brasil (H.M.)

\begin{abstract}
Resumo
São apresentados os resultados da avaliação da vacina antimeningocócica BC de procedência cubana realizada com dados da vigilância epidemiológica de meningites do Estado de Santa Catarina, Brasil, dos anos de 1990-92. A eficácia para os casos confirmados por exames bacteriológicos foi de $59 \%$ (IC de 95\%: 23 a 78\%) para os menores de 4 anos e de 78\% (IC de 95\%: 54 a 90\%) para as crianças de 4 a 7 anos. Com os casos confirmados como causados por sorogrupo B, as eficácias estimadas foram maiores, mas se ampliaram os intervalos de confiança. $\mathrm{O}$ efeito protetor da vacina em relação à mortalidade em crianças menores de 4 anos foi estimado em 76\% (IC 95\%: 41 a 91\%). Outros dados apresentados sugerem que as mais baixas eficácias encontradas, quando se analisam os menores de 4 anos, decorrem da seletividade da confirmação diagnóstica que exclui os casos mais graves que morrem a poucas horas do início dos sintomas, associada à modificação do curso da doença (atenuação) em vacinados. Por isso, indica-se a vacinação, inclusive em menores de 4 anos, nas situações epidêmicas.
\end{abstract}

Avaliação de ações de saúde pública (processo e resultado). Vacinas bacterianas, imunologia. Meningite meningocócica, prevenção \& controle.

\begin{abstract}
s
Results of the evaluation of the anti-meningococcal BC Cuban vaccine based on routine epidemiological surveillance information of meningitis for the years 1990 to 1992, following mass-vaccination of 232,022 children aged between 3 months and 7 years in 1989/90 during an epidemic of serogroup B meningococcal disease in the State of Santa Catarina, Brazil, are presented. The protective efficacy of the vaccine was calculated from the incidence rates for the cohort of vaccinated and non-vaccinated children in 20 municipalities. Main results for cases confirmed by bacteriological tests were 59\% (CI 95\%: 23 to
\end{abstract}


78\%) for children aged under 4 years and 78\% (CI 95\%: 54 to 90\%) for children aged 4 to 7 years. Eighty-six percent of cases serogrouped $(n=29)$ were $B$, and in these cases efficacy increased to $66 \%$ (<4 years) and $88 \%(4-7$ years), but at $95 \%$ CI were wider. The protective efficacy based on death rates from the disease in children $<4$ years was $76 \%$ (CI 95\%: 41 to 91\%). There was no evidence of decreasing protective efficacy in the three year follow-up, as shown by the yearly estimates. An interesting hypothesis arising from the findings is that the lower protective efficacy for children aged $<4$ years, observed in studies in which only cases confirmed by laboratory tests are analysed, could be due to a selective effect of this procedure. More severe cases die shortly after the onset of the disease, often before medical care is provided. On the other hand, the attenuation of the disease by vaccination gives a better chance for medical intervention and collection of samples for laboratory analysis. Finally, the authors support the use of the vaccine in epidemics of serogroup B meningococcal disease. They also suggest that three, rather than two doses of vaccine should be tested in children under 2 years of age to further increase its efficacy.

Evaluation of public health interventions (process and outcome). Bacterial vaccines, immunology. Meningitis, meningococcal, prevention and control.

\section{INTRODUÇÃO}

A doença meningocócica (DM) pelo sorogrupo $B$ vem crescendo em várias partes do Brasil, desde 1986. A memória da epidemia pelos sorogrupos C e A, da década de 1970, levou as autoridades sanitárias brasileiras a decidirem pela vacinação nos municípios de maior incidência nos anos 1989/90 com uma nova vacina, desenvolvida em Cuba, para enfrentar sua própria epidemia9.

Esse esforço se justificava pelo grave problema que tem representado as epidemias por meningococo, particularmente do sorogrupo B, que, no Brasil, como em Cuba, tem a letalidade em torno de $20 \%$, e 20 a $40 \%$ dos casos apresentam meningococcemia isolada ou acompanhada de meningite. Ademais as meningococcemias fazem da DM uma doença transmissível realmente fulminante: metade dos óbitos ocorre de 6 a 24 horas do início de sintomas inespecíficos, não sendo injustificado o temor da comunidade.

Os bons resultados obtidos no controle da doença em $\mathrm{Cuba}^{9} \mathrm{e}$ a gravidade da doença originaram alegações éticas à época da vacinação que invibializaram a realização de estudos com alocação aleatória da vacina.

Em 1993, uma Comissão Mista Brasil-Cuba ${ }^{1}$, constituída pelo Ministério da Saúde para avaliar os resultados da aplicação da vacina antimeningocócica BC (VA-MENGOC BC ${ }^{\circledR}$ ), no Brasil, baseada em dados coletados pelos Serviços de Vigilância Epidemiológica (SVE) de seis Estados, e em estudos tipo caso-controle realizados em São Paulo ${ }^{7}$ e Rio de Janeiro ${ }^{8}$, posicionou-se favoravelmente à utilização da vacina em situações epidêmicas. Logo após a divulgação da versão original do relatório, um dos membros da Comissão, que não participou da elaboração do texto final, firmou documento* discordando parcialmente das conclusões, baseado, entre outros argumentos, na precariedade das informações dos Estados, exemplificando com dados de Santa Catarina, onde a proteção conferida pela vacina para meningites virais, por exemplo, era maior do que para a doença meningocócica*.

A reavaliação do caso de Santa Catarina em profundidade, imperativa, foi realizada no final de 1993. Os resultados preliminares desse estudo já foram divulgados em relatório ao Ministério da Saúde** onde ficou demonstrado que a alta "proteção" contra meningites virais era devida a um erro de classificação do estado vacinal (todo caso com vacinação incompleta ou ignorada foi digitado como não vacinado). Mais importante, a avaliação de Santa Catarina, apresentada a seguir, forneceu elementos também para identificar viés de seleção de casos que afetou os resultados obti-

* J.C. Moraes - A vacina antimeningocócica BC de procedência cubana no Brasil. Documento enviado ao Ministro da Saúde. 9 de julho de 1993 . Dados inéditos.

** E. A. Costa - Nota Técnica sobre a avaliação da eficácia da vacina antimeningocócica BC em Santa Catarina, Brasil, 1990/92. Documento enviado ao Ministério de Saúde em 5 de janeiro de 1994. Dados inéditos. 
dos nos estudos caso-controle de São Paulo ${ }^{7}$ e do Rio de Janeiro ${ }^{8}$, já relatado em carta ao The Lancet*, em congresso médico ${ }^{2}$, e em nota prévia ${ }^{3}$.

\section{ALGUNS DADOS EPIDEMIOLÓGICOS}

Em 1987, 1988 e 1989 os coeficientes de incidência da DM em Santa Catarina foram, respectivamente, 6,6, 8,5 e 9,1 por cem mil habitantes. A série histórica de 1971 a 1991 está no Figura 1. Na década de 70 a epidemia foi pelos sorogrupos $\mathrm{Ce} \mathrm{A}$, sendo que a partir de 86 foi predominantemente pelo sorogrupo B. Em 101 cepas isoladas de 1986 a 1988, os sorotipos identificados** foram B:4 (18,8\%), B:8 (23,8\%), B:15 (24,8\%) e B:NT (não tipados) (32,7\%). Mais de $70 \%$ não tiveram o subtipo identificado. Quando identificados os subtipos foram P1.15 e P1.16 e apenas uma amostra P1.2. Em Cuba*** foram analisadas 9 cepas isoladas em 1990 de Santa Catarina, identificando 4 como B:4:P.15, 4 como B:15:P1.15 e 1 como B:2.

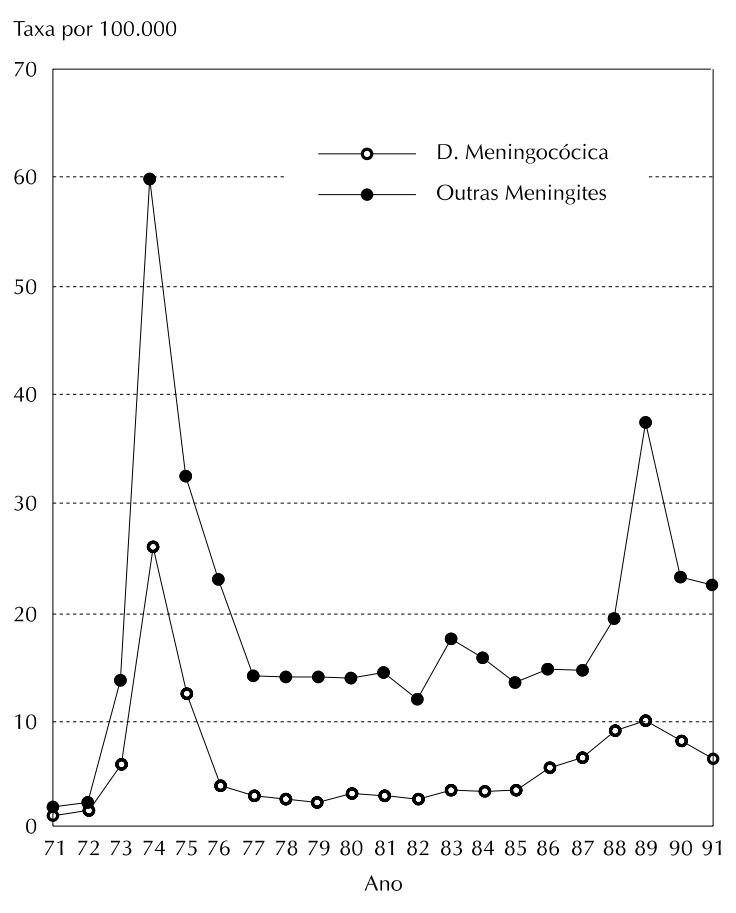

Figura 1 - Coeficientes de incidência da doença meningocócica e outras meningites em Santa Catarina, 1971-91. Fonte: Diretoria de Vigilância Epidemiológica da Secretaria Estadual de Saúde de Santa Catarina.
A vacina foi aplicada de outubro de 1989 a setembro de 1990 nos vinte municípios de maior incidência de Santa Catarina, no grupo etário mais atingido (de 3 meses a 7 anos de idade). A populaçãoalvo estimada era de 286.379 crianças, tendo sido vacinadas com duas doses $232.022(81,0 \%)$. Foram vacinadas 29.711 crianças com apenas uma dose. No total, dos vacinados com duas doses, $78 \%$ tiveram intervalo entre as doses de 5 a 15 semanas e $22 \%$ fora do mesmo.

Na Tabela 1 estão apresentados os dados de incidência de todas as meningites de 1989 a 1991, desdobrando a DM em suas formas clínicas (meningite meningocócica e meningococcemia). Verifica-se que a redução da incidência da DM, a partir de 1990, ano em que seriam esperados os efeitos da aplicação da vacina, se deu principalmente na forma meningococcêmica, mais grave. Nas Tabelas 2 e 3 (A e B) estão os dados de incidência e letalidade da DM para o total do Estado e para os municípios vacinados e não vacinados. Nessas tabelas são computados todos os casos notificados, o que significa que não se restringem aos casos pelo sorogrupo $\mathrm{B}$, que correspondiam a cerca de $85 \%$ dos casos tipados.

Como pode ser observado, na Tabela 2 a letalidade atinge $30 \%$ para as crianças menores de 2 anos e mais de $20 \%$ nas de 2 a 4 anos. Há nítida redução na incidência em 1990 relativo à 1989 nos grupos etários vacinados ( 3 meses a 7 anos) que se mantém em 1991, quando então se reduz também a incidência nos grupos etários não vacinados. O importante impacto aparente da vacinação observado na Figura 1 ganha consistência quando comparados municípios vacinados e não vacinados e grupos etários vacinado (3 meses a 7 anos) e não vacinado (Tabelas $3 \mathrm{~A}$ e B). Considerados os grupos etários menores de 10 anos, para uma primeira aproximação, verifica-se queda da incidência maior nos municípios vacinados (1989: 170; 1990: 101; 1991: 103 = redução de 39,4\%) do que nos não vacinados (1989: 132; 1990: 97; 1991: 118 = redução de 10,6\%). Nos grupos etários não vacinados, de 10 anos e mais, há tendência declinante em municípios vacinados (1989: 67; 1990: 56; 1991: 41), não verificada nos não vacinados (1989: 46; 1990: 64; 1991: 42). Observe-se que a redução nos grupos vacinados dos municípios vacinados se dá ainda em 1990, havendo, coerentemente, pelo envelhecimento da coorte de vacinados, elevação em 1991 para os menores de 2 anos e redução para os de 8 a 10 anos.

* E.A. Costa - "Protective efficacy of a serogroup B meningococcal vaccine". Letter to The Lancet, Dec, 29th, 1993, revised Feb, 24th, 1994.(Unpublished)

** Instituto Adolfo Lutz, São Paulo, SP.

*** Instituto Finlay, Cuba. 
Tabela 1 - Incidência das meningites segundo diagnóstico etiológico em Santa Catarina, 1988-91.

\begin{tabular}{lrrrrrrrr}
\hline Ano/ & \multicolumn{2}{c}{1988} & \multicolumn{2}{c}{1989} & \multicolumn{3}{c}{1990} & \multicolumn{3}{c}{1991} \\
Etiologia & $N^{\text {o }}$ casos & Taxa & $N^{\circ}$ casos & Taxa & $N^{\circ}$ casos & Taxa & $n^{\text {o casos }}$ & Taxa \\
\hline Doença meningocócica & 368 & 8,6 & 423 & 9,7 & 319 & 7,2 & 295 & 6,2 \\
$\quad$ Meningite & $(168)$ & 3,9 & $(187)$ & 4,3 & $(233)$ & 5,2 & $(208)$ & 4,3 \\
$\quad$ Meningococcemia & $(200)$ & 4,7 & $(236)$ & 5,4 & $(86)$ & 1,9 & $(87)$ & 1,8 \\
Tuberculose & 12 & 0,3 & 13 & 0,3 & 10 & 0,2 & 10 & 0,2 \\
Pneumocócica & 110 & 2,6 & 93 & 2,1 & 71 & 1,6 & 61 & 1,3 \\
Hemófilo & 44 & 1,0 & 63 & 1,4 & 61 & 1,3 & 70 & 1,5 \\
Virais & 279 & 6,5 & 1.061 & 24,3 & 448 & 10,0 & 517 & 10,8 \\
Outras determin. & 58 & 1,4 & 113 & 2,6 & 81 & 1,8 & 107 & 2,2 \\
Não especificadas & 301 & 7,0 & 270 & 6,1 & 243 & 5,4 & 236 & 4,9 \\
\hline \multicolumn{1}{c}{ Total } & 1.172 & 27,4 & 2.036 & 46,6 & 1.233 & 27,6 & 1.322 & 27,6 \\
\hline
\end{tabular}

Fonte: Diretoria de Vigilância Epidemiológica da Secretaria Estadual de Saúde de Santa Catarina (DVE-SES/SC).

Nota: Taxa por 100.000 habitantes estimados por projeção do censo de 1980. A DVE-SES/SC, quando forneceu a Tabela, não dispunha ainda dos dados do censo de 1991 .

Tabela 2 - Letalidade da doença meningocócica por grupo etário em Santa Catarina, 1989-91.

\begin{tabular}{|c|c|c|c|c|c|c|c|c|c|c|}
\hline \multirow{2}{*}{$\begin{array}{l}\text { Grupo } \\
\text { Etário }\end{array}$} & \multicolumn{3}{|c|}{1989} & \multicolumn{3}{|c|}{1990} & \multicolumn{3}{|c|}{1991} & \multirow{2}{*}{$\begin{array}{r}89 / 91 \\
\text { Let } \%\end{array}$} \\
\hline & Casos & Óbitos & Let $\%$ & Casos & Óbitos & Let $\%$ & Casos & Óbitos & Let $\%$ & \\
\hline$<2$ & 135 & 42 & 31,1 & 79 & 25 & 31,6 & 97 & 31 & 32,0 & 31,5 \\
\hline $2-4$ & 87 & 22 & 25,3 & 62 & 14 & 22,6 & 66 & 11 & 16,7 & 21,9 \\
\hline 5-9 & 85 & 8 & 9,4 & 57 & 7 & 12,3 & 58 & 2 & 3,4 & 8,5 \\
\hline $10-14$ & 46 & 5 & 10,9 & 43 & 7 & 16,3 & 23 & 0 & 0,0 & 10,7 \\
\hline $15-24$ & 39 & 5 & 12,8 & 42 & 8 & 19,0 & 22 & 2 & 9,1 & 14,6 \\
\hline $25-94$ & 28 & 4 & 14,3 & 35 & 5 & 14,3 & 28 & 4 & 14,3 & 14,3 \\
\hline Total & 420 & 86 & 20,5 & 318 & 66 & 20,8 & 294 & 50 & 17,0 & 19,6 \\
\hline
\end{tabular}

Cas $=$ todos os casos notificados com evolução conhecida.

Let $\%$ = letalidade (Óbi X $100 /$ Cas).

Tabela 3 - Casos notificados de doença meningocócica segundo critério de confirmação diagnóstica ${ }^{1,2}$ e grupo etário ${ }^{3}$ em Santa Catarina, 1989-91.

A. Municípios vacinados ${ }^{4}$ em 1989/90.

\begin{tabular}{lcccccccc}
\hline $\begin{array}{l}\text { Grupo } \\
\text { Etário } \\
\text { (anos) }\end{array}$ & \multicolumn{2}{c}{1989} & \multicolumn{2}{c}{1990} & \multicolumn{2}{c}{1991} & \multicolumn{2}{c}{$\begin{array}{c}\text { \% variação } \\
\text { (91/89) }\end{array}$} \\
\hline$<2$ & CBact & Todos & CBact & Todos & CBact & Todos & CBact & Todos \\
\hline $2-7$ & 48 & 76 & 23 & 40 & 33 & 47 & -31 & -38 \\
$8-10$ & 14 & 80 & 22 & 45 & 24 & 47 & -50 & -41 \\
$11-94$ & 51 & 24 & 16 & 23 & 6 & 9 & -57 & -63 \\
\hline Todos & 161 & 63 & 37 & 49 & 26 & 31 & -49 & -51 \\
\hline
\end{tabular}

B. Municípios não vacinados ${ }^{5}$ em 1989/90.

\begin{tabular}{lcccccccc}
\hline $\begin{array}{l}\text { Grupo } \\
\text { Etário } \\
\text { (anos) }\end{array}$ & \multicolumn{2}{c}{1989} & \multicolumn{2}{c}{1990} & \multicolumn{3}{c}{1991} & \multicolumn{2}{c}{$\begin{array}{c}\text { \% variação } \\
\text { (91/89) }\end{array}$} \\
\hline$<2$ & CBact & Todos & CBact & Todos & CBact & Todos & CBact & Todos \\
\hline-7 & 35 & 62 & 23 & 39 & 30 & 50 & -14 & -19 \\
$8-10$ & 37 & 64 & 31 & 49 & 36 & 60 & -3 & -7 \\
$11-94$ & 32 & 10 & 10 & 15 & 7 & 12 & -13 & +20 \\
\hline Todos & 112 & 44 & 47 & 58 & 34 & 38 & +6 & -14 \\
\hline
\end{tabular}

1- "Todos" são os casos notificados, independente do critério diagnóstico, incluem os CBact e os confirmados apenas clinicamente (meningococcemias) ou com química e citologia de líquor.

2- "CBact" correspondem aos casos confirmados por exame bacteriológico ou imunológico: bacterioscopia, cultura ou contra-imunoeletroforese

3- Os grupos etários vacinados foram de 3 meses a 7 anos. Isso quer dizer que em 1991 apenas uma parte dos menores de 2 anos havia sido vacinada.

No entanto, a maior parte dos de 8 a 10 anos nesse ano havia sido vacinada anteriormente.

4- São 20 municípios vacinados de outubro de 1989 a setembro de 1990 (a imunidade para os vacinados em 1989 só ocorreu em janeiro de 1990 e $90 \%$

das vacinas aplicadas foram antes de junho de 1990).

5- Demais municípios do Estado de Santa Catarina. 
Em resumo, apesar dos problemas de má classificação dos casos e da grande variabilidade do comportamento epidemiológico da DM, pode ser observado sensível impacto vacinal: antes da vacinação (1989) havia mais casos, em número absoluto, nos municípios vacinados em ambos grupos etários; no biênio seguinte os municípios não vacinados passaram a ter mais casos, acentuadamente no grupo etário de 2 a 7 anos, mas não só nesse. A redução da incidência nos grupos etários não vacinados, diferencialmente nos municípios vacinados, entre outras hipóteses, pode sugerir um efeito da vacinação na circulação da $N$. meningitidis.

Como o risco de adoecer deve ter sido diferente, afinal foram vacinados os grupos etários de maior incidência dos municípios selecionados por terem, também, maior incidência, é importante uma análise da eficácia (ou efetividade como preferem alguns autores) da vacina, comparando a incidência em crianças vacinadas e não vacinadas do mesmo grupo etário dos municípios vacinados.

\section{MÉTODOS PARA AVALIAÇÃO DA EFICÁCIA}

A Secretaria de Saúde do Estado de Santa Catarina informatizou em 1988 a vigilância epidemiológica das meningites. Iniciada a vacinação em 1989, foram incluídos nas fichas epidemiológicas dos casos seus dados vacinais. No arquivo eletrônico gerado, os casos de DM são classificados segundo sua forma clínica, em meningite meningocócica ou meningococcemia, com ou sem meningite, e podem ser classificados segundo os critérios diagnósticos: sorogrupados (confirmados por cultura ou contra-imunoeletroforese); confirmados por laboratório bacteriológico (sorogrupados ou com bacterioscopia positiva); confirmados por clínica (quadro de meningococcemia ou meningite aguda com lesões hemorrágicas de pele, com citologia e bioquímica de liquor compatível com esse diagnóstico). Para avaliar a eficácia da vacina foram utilizados os dados de 1990 a 1992.

\section{Registro dos Casos}

Em novembro de 1993, procedeu-se ao levantamento das fichas de todos os casos de meningite em menores de 11 anos, em municípios vacinados ou não, ocorridos em Santa Catarina nos anos de 90, 91 e 92, anotando, juntamente com o número do caso no ano, a situação vacinal, segundo as categorias: $S 2$ - vacinado com duas doses; $S 1$ vacinado com uma dose; $S 9$ - vacinado sem referência a doses; $N O$ - não vacinado; $I 9$ - ignorado ou em branco; $F A$ - fora do arquivo (ficha perdida). De posse desses dados, foram acrescentados aos arquivos eletrônicos, a situação vacinal. As demais variáveis do arquivo original de inte- resse são: município de residência, data do início da doença, idade, diagnóstico, critério diagnóstico, sorogrupo, evolução.

\section{Arquivo dos Casos da Coorte em Estudo}

Para a seleção dos casos da coorte em estudo e organização de arquivo especial para a análise final, foram selecionados os casos de DM confirmados por qualquer um dos três critérios diagnósticos, ocorridos em municípios onde houve vacinação. Foi construída uma variável especial: idade do paciente à época em que a vacinação do seu município de residência foi completada, mais um mês (para alcançar a imunidade). O caso foi selecionado para análise se sua idade, à época em que poderia ter sua imunidade completada, estivesse entre 5 e 95 meses. Assim, foi criada nova variável, com duas categorias de grupo etário da coorte de casos: 5 a 47 e 48 a 95 meses. Dos 175 casos selecionados para esse novo arquivo, dois não vacinados foram excluídos por estarem na coorte de cinco meses de idade, ficando duvidoso, pela data do adoecimento, se seriam ou não elegíveis à vacinação à época da campanha. Das dez fichas não localizadas nos arquivos da SVE para verificação do estado vacinal, apenas quatro preenchiam os critérios de idade para fazer parte desse arquivo de 173 casos. Em dez casos, com registro de vacina, não havia especificação de data ou número de doses. Esses 14 casos foram classificados como vacina ignorada, embora, nos registros originais do arquivo magnético constasse que 7 eram vacinados e 7 não eram vacinados. Outros 27 casos não tinham registro de situação vacinal (ignorada), completando 41 casos $(23,7 \%)$ em que essa informação não era aproveitável.

\section{Estimativas Populacionais}

As estimativas para a população-alvo de cada município vacinado foram refeitas com os dados do censo de 1991, fornecidos pela Fundação Instituto Brasileiro de Estatística (IBGE). Os dados são municipais e fornece, ano a ano, a idade. Como o censo foi realizado em setembro/outubro e a vacinação em Santa Catarina foi iniciada em outubro de 1989, estimou-se a população-alvo com os dados da coorte, ajustando pela experiência de mortalidade de dois anos do grupo, utilizando os dados do registro de óbitos fornecidos pela Secretaria de Saúde de Santa Catarina. Para o conjunto dos 20 municípios vacinados, no total, a nova estimativa ficou $14 \%$ menor do que a estimativa original da população-alvo; isso, como se sabe, devido à queda da fecundidade ocorrida em todo o País nessa última década.

\section{Estimativa Vacinal}

Os dados vacinais foram fornecidos pela Secretaria de Saúde de Santa Catarina, município a município, ano a ano de idade, com as datas da primeira e segunda dose da aplicação da vacina. Em três municípios, de maior porte, 
houve "repescagem" vacinal seis e oito meses depois da vacinação inicial, produzindo algumas distorções na avaliação da cobertura vacinal, como, por exemplo, mais vacinados com menos de um ano do que as estimativas existentes à época, pois faziam parte, de fato, de outra coorte de vacinados, não nascidas ao tempo da campanha original. Estimou-se a idade que teriam, alocando essas vacinações na coorte correta, ou as descartando, se fora da idade de vacinação. Desse modo, 8.762 vacinas aplicadas em menores de um ano, vários meses depois da campanha original, foram descartadas, sendo aproveitadas 223.260 vacinações completas. Por fim, foi estimado o número de vacinados de municípios vizinhos aos municípios escolhidos para a vacinação. Para isso, tomou-se a proporção de casos de meningites vacinados residentes em municípios vacinados e em municípios não vacinados, calculando o risco de um caso não residente ser vacinado, relativo ao do de um residente (municípios não vacinados: 3 vacinados em 246 casos; municípios vacinados: 85 vacinados dentre 363; razão de produtos cruzados $=0,04)$. Aplicouse um redutor de $5 \%$ (25\% maior) nas estimativas de vacinados dos municípios vacinados.

\section{Cálculo dos Denominadores (Pessoas-Ano)}

O número de imunizados (vacinados) e não imunizados (não vacinados), em 1990, foi se modificando ao longo do ano, sendo incorporados novos contingentes a cada mês durante um ano. Com os dados disponíveis, calculou-se o número de pessoas-mês vacinados e não vacinados para a construção do denominador, de pessoas-tempo. Os resultados obtidos podem ser verificados na Tabela 4 , que indica a cobertura vacinal final, na coorte estudada, de $81,7 \%(82,4$ para os de 5 a 47 meses e $81,1 \%$ para os de 48 a 95 meses de idade).

Tabela 4 - Coortes de pessoas-ano vacinadas e não vacinadas em 20 de municípios* de Santa Catarina, 1990-1992.

\begin{tabular}{cccc}
\hline $\begin{array}{l}\text { Grupo Etário } \\
\text { (meses) }\end{array}$ & Vacinados & Não vacinados & Total \\
\hline 5 a 47 & 94.311 & 20.185 & 114.496 \\
48 a 95 & 105.930 & 24.620 & 130.550 \\
5 a 95 & 200.241 & 44.805 & 245.046 \\
\hline
\end{tabular}

* Somente aqueles em que ocorreu vacinação.

\section{Computação Eletrônica}

Os arquivos eletrônicos de Santa Catarina foram transferidos para análise com o sistema Epi-Info ${ }^{4}$, sendo utilizados os cálculos dos riscos relativos para determinar a eficácia da vacina e seus intervalos de confiança de $95 \%$. Os valores globais foram ajustados por estratificação segundo os grupos etários, ponderados de acordo com a exposição ${ }^{5}$.

\section{RESULTADOS}

A Figura 2 mostra a incidência da DM na coorte do estudo, acumulada mês a mês, nos três anos de observação. Ainda que aos vacinados se acrescentas-

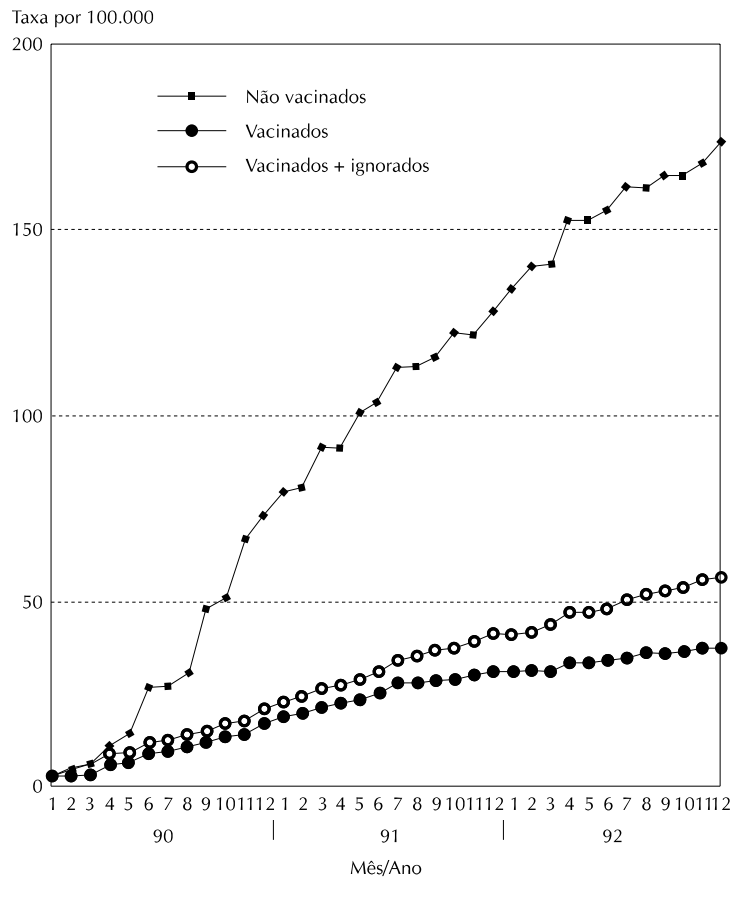

Figura 2 - Doença meningocócica em municípios vacinados de Santa Catarina. Taxa mensal acumulada por 100.000, segundo estado vacinal, 1990-92.

Notas: Taxa para vacinados e para vacinados+ignorados calculada sobre a coorte (idades de 5 a 95 meses de janeiro a junho de 1990) vacinada com VA-MENGOC $\mathrm{BC}^{\circledast}$. Taxa para não vacinados calculada sobre a coorte da mesma idade não vacinada.

sem todos os com situação vacinal ignorada, a taxa final em não vacinados foi cerca de três vezes maior.

A eficácia para todos os casos de DM (confirmados por laboratório ou clínica) foi de $69 \%$ (IC 95\%: 57 a $78 \%$ ), pouco variando quando comparados os dois grupos etários (Tabela 5).

Para os casos confirmados por laboratório (bacteriológico), como pode ser observado na Tabela 6 , a eficácia global da vacina foi de 68\% (IC 95\%: 49 a $80 \%$ ), alcançando $78 \%$ (IC 95\%: 49 a $91 \%$ ) para os sorogrupados B. Para os menores de 4 anos a eficácia foi de 59\% (66\% para os sorogrupados B) e, para os maiores de 4 anos, de $78 \%$ (88\% para os sorogrupados B).

Tabela 5 - Estimativa de eficácia da VA-MENGOC BC ${ }^{\circledR}$ com todos os casos de doença meningocócica da coorte de Santa Catarina, 1990 a 1992.

\begin{tabular}{ll}
\hline Grupo Etário Vacinados Não vacinados & $\begin{array}{c}\text { Eficácia } \\
\text { (IC 95\%) }\end{array}$
\end{tabular}

\begin{tabular}{cccc} 
(meses) & $(\mathrm{n})$ & $(\mathrm{n})$ & $(\%)$ \\
\hline $5-47$ & 52 & 35 & $68 \%(51$ a $79 \%)$ \\
$48-95$ & 25 & 20 & $71 \%(48$ a $84 \%)$ \\
\hline Total & 77 & 55 & $69 \%(57$ a $78 \%)$ \\
\hline
\end{tabular}


Tabela 6 - Casos de doença meningocócica confirmados laboratorialmente* e eficácia da vacina estimada em Santa Catarina, 1990 a 1992.

\begin{tabular}{cccc}
\hline $\begin{array}{c}\text { Grupo Etário } \\
\text { (meses) }\end{array}$ & $\begin{array}{c}\text { Vacinados } \\
\text { (Sorogrupo B) }\end{array}$ & $\begin{array}{c}\text { Não vacinados } \\
\text { (Sorogrupo B) }\end{array}$ & $\begin{array}{c}\text { Eficácia; IC 95\% } \\
\text { (Sorogrupo B) }\end{array}$ \\
\hline $5-47$ & 29 & 15 & $59 \% ;+23$ a $78 \%$ \\
& $(8)$ & $(5)$ & $(66 \% ;-5$ a $89 \%)$ \\
$48-95$ & 13 & 14 & $78 \% ;+54$ a $90 \%$ \\
& $(3)$ & $(6)$ & $(88 \% ;+54$ a $97 \%)$ \\
\hline Todos & 42 & 29 & $68 \% ;+49$ a $80 \%$ \\
& $(11)$ & $(11)$ & $(78 \% ;+49$ a $91 \%)$ \\
\hline
\end{tabular}

* Confirmados por bacterioscopia, contra-imunoeletroforese ou cultura do líquor.

( ) Entre parêntesis resultados para os casos sorogrupados B.

O período de observação foi de 3 anos, com uma incidência da doença claramente decrescente. Considerados todos os casos diagnosticados como sendo de DM, em 1990, na coorte ocorreram 35 em vacinados e 22 em não vacinados; em 1991, 29 em vacinados e 18 em não vacinados; e, em 1992, 13 e 15, respectivamente. A eficácia da vacina, ano a ano, para todos os casos foi: em 1990 de 64\% (IC de 95\%: 39 a $79 \%$ ); em 1991 de 64\% (IC de 95\%: 35 a $80 \%$ ); em 1992 de $81 \%$ (IC de 95\%: 59 a 91\%), mostrando que não caiu ao longo desses três anos. Embora o aumento no terceiro ano não seja estatisticamente significativo, e possa ter ocorrido pela diminuição da incidência do sorogrupo B e aumento relativo dos casos por $\mathrm{C}$, é possível também que o relaxamento na coleta de dados vacinais no terceiro ano tenha aumentado os erros de classificação.

De particular interesse, numa epidemia de uma doença com letalidade de cerca de $20 \%$, pela alta proporção de formas acompanhadas por toxemia, é escrutinar o possível efeito da vacina na redução da gravidade. Os dados de todos os casos do arquivo mostram uma letalidade global de $17,9 \%$, sendo de 6,8\% nas meningites meningocócicas (MM) e 34,3\% nos casos diagnosticados como meningococcemia (MC), que representaram 40,5\% do total de casos de doença meningocócica. A letalidade foi sempre menor nos vacinados do que nos não vacinados, quer nos casos de $\mathrm{MM}(2,6$ e 5,6\%, respectivamente), quer nos de MC (26,3 e 42,1\%). Essas diferenças, consistentes em ambos os grupos de idade, não são, no entanto, significantes (alfa $=5 \%$ ). Os 41 casos sem situação vacinal definida (ignorada, fora do arquivo e não especificada) apresentaram letalidade elevada $(24,4 \%)$ que, nas meningococcemias, foi de $46,2 \%$. Esses valores são semelhantes aos encontrados para os casos não vacinados.

De outro lado, as estimativas de proteção conferida pela vacina contra óbitos por doença meningocócica, em particular em menores de 4 anos, pelo problema epidemiológico, médico e familiar, são im- portantes. Se todos os óbitos forem considerados, inclusive aqueles, por se tratarem de meningococcemias, só com confirmação clínica, os resultados são:

- para doença meningocócica (MM+MC),

de 5 a 47 meses - eficácia de 76\% (IC de 95\%: 41 a $91 \%$ ),

de 5 a 95 meses - eficácia de 76\% (IC de 95\%: 44 a $90 \%)$;

- para meningococcemia (MC),

de 5 a 47 meses - eficácia de 72\% (IC de 95\%: 26 a $90 \%$ ),

de 5 a 95 meses - eficácia de 73\% (IC de 95\%: 32 a $89 \%$ ).

Quando esta mesma análise se restringe aos casos confirmados por laboratório, efeitos importantes se manifestam, conforme os dados seguintes: de início são eliminados da análise 22 dos 103 casos de MM $(21,4 \%)$ e 57 dos 70 casos de MC $(81,4 \%)$, e, depois, são eliminados 4 dos 7 óbitos por MM $(57,1 \%)$ e 18 dos 24 óbitos por MC (75\%). Assim, são eliminados da análise os casos mais graves da doença, via de regra as formas meningococcêmicas, particularmente em menores de 4 anos, cujo óbito é fulminante, sem condições diagnósticas e de tratamento. Nesses casos, em geral, o diagnóstico bacteriológico é difícil tanto em Santa Catarina, como no resto do Brasil, particularmente por não haver tradição de se utilizar rotineiramente o sangue para hemocultura ou esfregaço para exame direto de lesões cutâneas.

Porém, mais ainda, um surpreendente efeito se relaciona à seletividade vacinal da exclusão dos casos de meningococcemia sem diagnóstico laboratorial e suas conseqüências para o cálculo da eficácia da vacina em menores de 4 anos. Na Tabela 7 , pode-se verificar que dos 38 casos de MC vacinados, $11(28,9 \%)$ tiveram confirmação laboratorial, já entre os não vacinados, apenas $1(5,3 \%)$ dos 19 casos foi confirmado ( $\mathrm{p}=0,045)$. Esse efeito seletivo não ocorre com a MM (31/39 nos vacinados e 28/38 
Tabela 7 - Casos de meningococcemias e de meningite meningocócica em vacinados e não vacinados. Santa Catarina, 199092.

\begin{tabular}{|c|c|c|c|c|c|c|c|c|c|c|c|c|}
\hline \multirow{3}{*}{$\begin{array}{l}\text { Grupo } \\
\text { Etário } \\
\text { (meses) }\end{array}$} & \multicolumn{6}{|c|}{ Meningococcemia } & \multicolumn{6}{|c|}{ Meningite meningocócica } \\
\hline & \multicolumn{3}{|c|}{ Vacinados } & \multicolumn{3}{|c|}{ Não vacinados } & \multicolumn{3}{|c|}{ Vacinados } & \multicolumn{3}{|c|}{ Não vacinados } \\
\hline & Todos & CBact & $(\%)$ & Todos & CBact & $(\%)$ & Todos & CBact & $(\%)$ & Todos & CBact & $(\%)$ \\
\hline 5 a 47 & 25 & 7 & $(28,0)$ & 15 & 1 & $(6,7)$ & 27 & 22 & $(81,5)$ & 20 & 14 & $(70,0)$ \\
\hline 48 a 95 & 13 & 4 & $(30,8)$ & 4 & 0 & $(0,0)$ & 12 & 9 & $(75,0)$ & 16 & 14 & $(87,5)$ \\
\hline 5 a 95 & 38 & 11 & $(28,9)$ & 19 & 1 & $(5,3)$ & 39 & 31 & $(79,5)$ & 36 & 28 & $(77,8)$ \\
\hline
\end{tabular}

Todos - Corresponde ao total de casos diagnosticados, com confirmação clínica com ou sem confirmação laboratorial.

CBact - Corresponde apenas aos casos confirmados por exames laboratoriais: bacterioscopia, contra-imunoeletroforese ou cultura.

Tabela 8 - Eficácia da vacina cubana para prevenir casos e óbtios em menores de 4 anos. Santa Catarina, $1990 / 93$.

\begin{tabular}{|c|c|c|c|c|c|c|c|}
\hline \multirow[t]{2}{*}{ Forma clínica } & \multirow[t]{2}{*}{ Critério diagnóstico } & \multirow[t]{2}{*}{ Evolução } & \multicolumn{2}{|c|}{ Não vacinados } & \multicolumn{2}{|c|}{ Vacinados } & \multirow[t]{2}{*}{ Eficácia (IC) } \\
\hline & & & $\mathrm{n}$ & $(\%)$ & $\mathrm{n}$ & $(\%)$ & \\
\hline \multirow[t]{4}{*}{ Meningococcemia } & Todos & Casos & 15 & (37) & 25 & (63) & $64 \%(32$ a 81$)$ \\
\hline & & Óbitos & 7 & (44) & 9 & (56) & $72 \%(26$ a 90$)$ \\
\hline & CBact & Casos & 1 & (12) & 7 & $(88)$ & $-48 \% p>0,05$ \\
\hline & & Óbitos & 0 & $(0)$ & 5 & $(100)$ & - \\
\hline \multirow[t]{4}{*}{ Meningite Meningoc. } & Todos & Casos & 20 & (42) & 27 & (58) & $71 \%(48$ a 84$)$ \\
\hline & & Óbitos & 2 & $(67)$ & 1 & (33) & $89 \% p>0,05$ \\
\hline & CBact & Casos & 14 & (39) & 22 & (61) & $66 \%(34$ a 83$)$ \\
\hline & & Óbitos & 0 & (0) & 0 & $(0)$ & - \\
\hline \multirow[t]{4}{*}{ Ambas } & Todos & Casos & 35 & (40) & 52 & $(60)$ & $68 \%(51$ a 79$)$ \\
\hline & & Óbitos & 9 & $(47)$ & 10 & (53) & $76 \%(41$ a 91$)$ \\
\hline & CBact & Casos & 15 & (34) & 29 & (66) & $59 \%(23$ a 78$)$ \\
\hline & & Óbitos & 0 & $(0)$ & 5 & $(100)$ & - \\
\hline
\end{tabular}

(IC) - intervalo de confiança de $95 \%$.

Todos - inclui todos os casos diagnosticados.

CBact- só inclui os positivos por bacterioscopia, cultura ou contra-imunoeletroforese.

nos não vacinados). Como conseqüência desse fenômeno seletivo, as eficácias calculadas, particularmente para os menores de 4 anos, diminuem quando se analisam apenas os casos confirmados por laboratório (Tabela 8), ficando negativa para os casos de meningococcemia.

Esses resultados mostram que a exclusão da análise dos casos sem confirmação bacteriológica teve efeito redutor da eficácia de ponto por excluir diferencialmente a DM em não vacinados.

\section{DISCUSSÃO}

Entre as fontes de possíveis erros de estudos de avaliação de intervenção não planejada, como apresentado, deve-se considerar:

1 - Estimativas de não vacinados a partir de população-alvo, obtida por projeções podem gerar problemas tão mais sérios quanto maiores forem as coberturas vacinais. No caso presente foi possível contar com dados censitários, em época próxima da vacinação.

2 - A população total de vacinados poderia ter incluído muitas pessoas de fora da área definida, de modo que a cobertura vacinal teria, de fato, sido menor do que a calculada. Com os dados dos municípios não vacinados foi possível estimar esse efeito e corrigir os dados dos municípios vacinados.

3 - As crianças vacinadas de forma incompleta (só uma dose) foram classificadas como não vacinadas. Portanto, os doentes com registro de apenas uma dose de vacina foram também considerados não vacinados. Os vacinados com uma dose representaram, ao final, $12,8 \%$ dos vacinados com duas doses, enquanto os casos com uma dose representaram $9,1 \%$ em relação aos casos com duas doses. Esse dado poderia indicar, como observou Noronha ${ }^{8}$, que uma dose da vacina deve dar alguma proteção. Daí porque o resultado final de incluir os com uma dose entre não vacinados seria subestimar a eficácia.

4 - Os não vacinados, via de regra, estão submetidos a risco maior de adoecer, uma vez que deveriam ser, supostamente, os mais pobres, que tinham menor acesso aos serviços de saúde e menor informação, e os que viviam em domicílios com mais pessoas ou em alojamentos coletivos. Esse senso comum refere-se, todavia, às condições sociais e epidemiológicas das grandes cidades. Isso não necessariamente ocorreu em Santa Catarina: a capi- 
tal não foi vacinada. No interior as crianças não vacinadas mais freqüentemente viviam na área rural, onde a exposição ao risco de adoecer tende a ser menor. Enquanto cerca de $10 \%$ dos casos desse estudo provinham de área rural, o censo de 1991, para os mesmos municípios, registrou $16 \%$ residentes nessa área. Em outras palavras, ao invés de superestimar a eficácia, a não aleatorização da aplicação da vacina pode estar, também, subestimando-a.

5 - Crítica comum, a favor de estudos caso-controle, é que no tipo de estudo aqui descrito não se pode ajustar os resultados por variáveis de confusão, inclusive a descrita no item anterior. No entanto, como Noronha ${ }^{8}$ registra, o cálculo da eficácia bruta para o sorogrupo B no Município do Rio de Janeiro foi de $45 \%$ e $82 \%$ para os grupos etários, respectivamente, de menos de 4 anos e de 4 anos e mais, enquanto depois de ajustada por análise multivariada, com todas as variáveis significantes, passou a $67 \%$ e $80 \%$. Ou seja, a introdução das variáveis de confusão no grupo etário de menos de 4 anos, de fato, aumentou a estimativa da eficácia, sugerindo, mais uma vez, que os presentes métodos podem estar subestimando a eficácia.

6 - A anotação vacinal dos casos nos registos da SVE foi muitas vezes baseada em informações orais, podendo gerar viés. De outro lado, os 27 casos com informação vacinal ignorada, adicionados de 4 casos com fichas perdidas e 10 casos em que foi registrado que era vacinado, mas não era informado o número de doses ou data, resultou em alta pro- porção de perdas $(41 / 173=23,7 \%)$. A letalidade desses casos sugere que de fato, em sua maioria, eram não vacinados. Assim, é razoável pensar que as estimativas de eficácia ficaram subestimadas. Mas, ainda que não tenha introduzido um viés em qualquer direção, a retirada desses casos da análise aumentou a amplitude dos intervalos de confiança das estimativas de eficácia.

7 - A proporção de casos com confirmação laboratorial, e, ainda mais, se confirmados como sendo do sorogrupo B, é pequena. Com isso, os intervalos de confiança ficam muito ampliados, perdendo-se potência para os testes de hipótese. De outro lado, as eficácias para o total dos casos sem sorotipagem ou sem confirmação laboratorial tenderão a ser subestimadas por incluir outros diagnósticos. No presente estudo, entretanto, foi encontrado efeito paradoxal, eficácias maiores quando se admitem diagnósticos menos precisos, devido ao viés de seleção exposto. Isto indica que as eficácias mais altas, quando são incorporados os casos com confirmação clínica de meningococcemia, devem, ainda, estar subestimando a verdadeira eficácia da vacina.

Na Tabela 9 constam os resultados comparativos com os dois estudos caso-controle ${ }^{7,8}$, além de estudo do poder bactericida realizado em São Paulo*.

Esses estudos de caso-controle geralmente apresentam viés de seleção e dificuldades na comparabilidade dos grupos. Embora uma análise do estudo de São Paulo tenha sido publicada ${ }^{3}$, há claros problemas com o mesmo que merecem comentários aqui. Em relação à parte retrospectiva do estudo: os con-

Tabela 9 - Eficácia da VA-MENGOC BC ${ }^{\circledR}$ no Brasil: estudos realizados no período 1990-93.

\begin{tabular}{|c|c|c|c|c|c|}
\hline \multirow{3}{*}{$\begin{array}{l}\text { Grupo } \\
\text { de Etário } \\
\text { (meses) }\end{array}$} & \multirow{3}{*}{$\begin{array}{l}\text { \% de aumento } \\
\text { em } 2 \text {-vezes do } \\
\text { poder bacter. }\end{array}$} & \multicolumn{3}{|c|}{ Estudos caso-controle } & \multirow{3}{*}{$\begin{array}{c}\text { Avaliação } \\
\text { S.Catarina**** } \\
\text { (i.c. } 95 \% \text { ) }\end{array}$} \\
\hline & & São Paulo** & \multirow{2}{*}{\multicolumn{2}{|c|}{$\begin{array}{l}\text { Rio de Janeiro*** } \\
\text { Estado Município }\end{array}$}} & \\
\hline & & & & & \\
\hline$<24$ & $49 \%$ & $5 \%(\mathrm{~ns})$ & $10 \%(\mathrm{~ns})$ & $47 \%(\mathrm{~ns})$ & $55 \%(\mathrm{~ns})$ \\
\hline $24-47$ & $64 \% *$ & $53 \%(\mathrm{~ns})$ & $41 \%(\mathrm{~ns})$ & $69 \%(n s)$ & $62 \%(14$ a 83$)$ \\
\hline$<48^{* * * * *}$ & $57 \%$ & $33 \%(n s)$ & $26 \%(\mathrm{~ns})$ & $64 \%(n s)$ & $59 \%(23$ a 78$)$ \\
\hline $48-83$ & $70 \%$ & $73 \%$ & & & \\
\hline $48-95$ & & & & & $78 \%(54$ a 90$)$ \\
\hline $48-119$ & & & $71 \%$ & $82 \%$ & \\
\hline Total & $64 \%$ & $54 \%$ & $54 \%$ & $74 \%$ & $68 \%(49$ a 80$)$ \\
\hline
\end{tabular}

(ns): não significante a $5 \%$

números grifados : $\mathrm{p}<0,05$

* Resultados divulgados pelo Instituto Adolfo Lutz de exames realizados antes e depois da vacinação em São Paulo ${ }^{6}$.

** Referente aos casos "definidos" - confirmados do sorogrupo B - do trabalho de Moraes, Perkins e col. ${ }^{7}, 1992$ (controles comunitários). Eficácia

global e para $<48$ meses calculadas pelos autores.

*** Referente ao estudo de Noronha ${ }^{8}, 1993$ (casos confirmados como sorogrupo B; controles hospitalares); a subdivisão nos grupos de menos de 4 anos foi fornecida em 1994 a pedido dos autores.

**** Presente trabalho, resultados para todos os casos de doença meningocócica confirmados por laboratório (quando sorogrupados $86 \%$ eram B) $* * * * *$ Subtotal, resultados combinados dos dois grupos de $<48$ meses.

* Melles C.E.A. - Centro de Referência Nacional para Meningites -Atividades da Seção de Bacteriologia, Instituto Adolfo Lutz, na avaliação da resposta imune de crianças vacinadas contra $N$. meningitidis B e C. São Paulo, 6 de julho de 1993. Dados inéditos. 
troles comunitários foram selecionados a um tempo em que a vacinação havia sido realizada apenas em orfanatos e outras instituições fechadas. Enquanto a estimativa de cobertura vacinal era de $12 \%$, segundo o mesmo trabalho, dos seus controles apenas 5\% eram vacinados. A partir dos dados apresentados no citado estudo é possível estimar que, embora não significante, a vacina nesse segmento dos dados teria uma eficácia negativa, o que, portanto, não surpreende. Além disso, controles de vizinhança para avaliar medidas preventivas em doenças transmissíveis geram efeito subestimador da eficácia por superpareamento (se a medida tiver eficácia), pois os casos tenderão a ocorrer nos locais de menores coberturas vacinais. Finalmente, ao utilizar casos de hospital de referência, certamente foram incluídos no estudo aqueles mais benignos, incorporando preferentemente os vacinados.

Os controles hospitalares (outras meningites) do estudo do Rio de Janeiro, ensejam dúvidas sobre quão adequados possam ser como representativos de nãocasos. Além do mais, casos e controles foram selecionados de apenas um hospital, e o mesmo, embora capte alta proporção de casos de doença meningocócica, capta proporcionalmente menos meningites virais. Como consequiência, o número de controles para os casos de fora do Município do Rio de Janeiro foi muito pequeno. Também, do mesmo modo que ocorreu em São Paulo, foram incorporados, via de regra, os casos mais benignos, particularmente os do interior do Estado que, pelas distâncias maiores, não ensejam oportunidade para as meningococcemias serem transferidas para o hospital de referência. De fato, a letalidade dos casos do estudo do Rio de Janeiro $^{8}$ foi $9 \%$, sendo a maioria dos óbitos tardios, enquanto a letalidade no total do Estado, no período, era de $20 \%$. Dentro do próprio hospital foi possível determinar que os casos incorporados ao estudo tinham menor letalidade do que os não incorporados, por falta de informação vacinal ou de confirmação diagnóstica.

Consideração metodológica pertinente é que, se os estudos do tipo caso-controle têm várias vantagens, inclusive estimar a baixo custo variáveis de confusão e permitir refinar o diagnóstico dos casos e a classificação do fator de risco (ou proteção), sofrem eles de uma incerteza costumeira ${ }^{6}$ : casos e controles do estudo representam (estatisticamente) a população de casos e a comunidade de onde provêm? No caso particular dos estudos aqui descritos, certamente não representam.

Por oportuno, podemos dizer que estudo da coorte natural, baseada em dados da rotina dos serviços, menos conceituada como regra cientificista, pode mostrar, como no caso presente, o que os estudos caso-controle escondem. Os "ignorados", tão comuns na rotina, nos caso-controles, em geral, inexistem: uns poucos são esclarecidos, mas a maioria deles são excluídos dos estudos. Portanto, nas coortes naturais se tem uma idéia da precariedade dos dados, nos caso-controles só aparecem os dados de "boa qualidade". Ademais, significantes variáveis de confusão, afora idade e sexo, costumam ter pouco efeito nas estimativas.

Os dados de Santa Catarina, especialmente a identificação do viés de seleção de casos, em função da rápida evolução fatal e provável atenuação da doença em vacinados, indicam que os estudos caso-controle encontraram estimativas baixas da eficácia em menores de 4 anos que têm maior letalidade nas primeiras horas do início dos sintomas, por se basearem em casos de hospitais de referência e desses, nos confirmados por cultura, via de regra do líquor, o qual nas meningococcemias é inicialmente negativa.

Na medida em que, exatamente em menores de 2 anos, a incidência, a proporção de formas graves, a mortalidade e a letalidade são maiores, para eles as estimativas de eficácia ficam mais subestimadas. Devemos lembrar que a avaliação do poder protetor do polissacáride $\mathrm{C}$, realizado em São Paulo, na década de 70 , em menores de 3 anos ${ }^{10}$ pode também ter sido prejudicada pelo viés de seleção aqui descrito.

$\mathrm{O}$ aprofundamento da análise do efeito da aplicação da vacina antimeningocócica BC em Santa Catarina veio confirmar os resultados encontrados pela Comissão Mista Brasil-Cuba ${ }^{1}$, que mostraram uma proteção de $72 \%$ para o sorogrupo $\mathrm{B}$, nos menores de 7 anos. Ainda que a proteção estimada seja mais alta para as crianças acima de 4 anos do que nas de menos de 4 anos, é muito provável que, corrigidos os viéses de seleção de casos dos estudos, essa diferença seja pequena. De qualquer forma, a vacina desempenha fator bastante favorável em relação à prevenção de óbitos (eficácia de 76\%, com intervalo de confiança de $95 \%$ de 41 a 91\%) em ambos grupos etários.

A partir desses dados, para a definição da utilização da vacina em programas de controle, corroborando a opinião da Comissão Mista Brasil-Cuba, resumidamente, pode-se afirmar que com o conhecimento atual, a vacinação de crianças menores de 4 anos também deve ser considerada numa epidemia, especialmente se a letalidade for alta, dependendo de uma avaliação da magnitude da mesma e do custo do produto. Nessa circunstância, corrigindo os problemas diagnósticos e de registro de situação vacinal, pode servir para esclarecer melhor o nível de proteção con- 
ferido pela vacina nessa faixa etária. Para os menores de 24 meses urge que se organize uma investigação planejada e controlada, oferecendo a um grupo duas doses da vacina, como hoje preconizado, e três doses para outro grupo, como utilizado na maioria das vacinas bacterianas em crianças de pouca idade, visando a ampliar a proteção oferecida.

\section{REFERÊNCIAS BIBLIOGRÁFICAS}

1. COMISSÃO MISTA BRASIL-CUBA. Relatório para o Ministério da Saúde do Brasil - Brasília, 7 de abril de 1993. Revisado: Havana, dezembro de 1993. Inf. Epidemiol. SUS, 3: 7-32, 1994.

2. COSTA, E.A.; AMARAL, C.; JUAREZ, E. Eficácia da vacina antimeningocócica (VA-MENGOC BC ${ }^{\circledR}$ ) nas condições de uso no Brasil no período 1989/90. Inf. Epidemiol. SUS, 3: 35-9, 1994.

3. COSTA, E.A. On the controversy about the efficacy of the antimeningococcal B vaccine: methodological pitfalls. $\mathrm{Cad}$. Saúde Pública, 11: 332-5, 1995.

4. DEAN, J.A.; DEAN, A.G; BURTON, A.; DICKER, R. EpiInfo, version 5: a word processing, database and statistics program for epidemiology on microcomputers. Stone Mountain, Georgia, USD Incorporated, 1990.

5. GREENLAND, S.\& ROBINS, J.M. Estimation of a common effect parameter from sparse follow-up data. Biometrics, 141: $55-68,1985$.

6. LICHTENSTEIN, M.; MULROW, C.; ELWOOD, P. Guidelines for reading case-control studies. J. Chron. Dis., 40: 893-903, 1987.

\section{AGRADECIMENTOS}

À Secretaria Estadual de Saúde de Santa Catarina, em particular a Antonio Ferreira Andrade, Isaias Medeiros Viana e Oswaldo Vitorino de Oliveira, e aos membros da Comissão Mista Brasil-Cuba, pela colaboração.

7. MORAES, J.C.; PERKINS, B.A.; CAMARGO, M.C.C.; HIDALGO, N.T.R.; BARBOSA, H.A.; SACCHI, C.T.; GRAL, I.M.L.; GATTAS, V.L.; VASCONCELOS, H.G.; PLIKAITIS, B.D.; WENGER, J.D.; BROONE, C.V. Protective efficacy of a serogroup B meningococcal vaccine in São Paulo, Brazil. Lancet, 2: 1074-8, 1992.

8. NORONHA, C. Avaliação da eficácia da vacina antimeningocócica B no Rio de Janeiro: um estudo casocontrole. Rio de Janeiro, 1993. [Dissertação de Mestrado, Escola Nacional de Saúde Pública. FIOCRUZ].

9. SIERRA, G.V.; CAMPA, H.C.; VARCACEL, N.M.; GARCIA, I.L.; IZQUIERDO, P.L.; SOTOLONGO, P.F.; CASANUEVA, G.V.; RICO, C.O.; RODRIGUEZ, C.R.; TERRY, M.H. Vaccine against group B Neisseria meningitidis: protection trial and mass vaccination results in Cuba. NIPH Ann. 14: 195-207, 1991.

10 - TAUNAY, A.E.; FELDMAN, R.A.; BASTOS, C.O.; GALVÃO, P.A.A.; MORAIS, J.S.; CASTRO, I.O. Avaliação do efeito protetor da vacina polissacarídica antimeningocócica do grupo C, em crianças de 6 a 36 meses. Rev. Inst. Adolfo Lutz, 38: 77-82, 1978. 